\title{
A RELIABILITY MODEL USING MARKOV CHAINS FOR UTILITY \\ EVALUATION OF COMPUTER SYSTEMS ONBOARD SHIPS
}

\author{
Carsten Bøe, 'Tor Heimly and Tor-Christian Mathiesen \\ Det norske Veritas \\ Oslo, Norway
}

\begin{abstract}
Introduction of computers onbsard ships to provide a high legree of automation necessitates ca'.culation of computer system reliability to evaluate the utility of the system. The reliability aspect of the system is simulated by a model using Markov chains. Having defined the system state space and the transition rates, the rnodel provides evaluation of the state probabilities. Evaluation of system utility is uased on computer task values and the failure probabilities. Application of the analysis mociel to an existing system reveals information useful in assigning redundancy, eliminating bottle-necks and allocating spare parts.
\end{abstract}

\section{INTRODUCTION}

The trend towaris still higher degrees of automation of macninery plant functions, has increasingly itvolved the electronic computer as an importani active device onboard ships. Primarily, the computer is used to perform monitoring tasks as alarm . d safety functions, but also to perform functions as condition monitoring of important components within the machinery plant, and active on-line tasks as bridge control functions, hull monitoring functions and loading/unloading calculations, to 
mention a few.

Regarding the safety of a ship, one of the rost interesting aspects of computerized ship functions is the supervision and automatic control of the machinexy plant and especially of the propulsion machinery. In this respect, the requirements of Det norske Veritas as a ship classification society should be mentioned. Already in 1965, Det norske reritas introduced as the first classification society, rules applying to the instrumentation of rachinery plants, intended for periodically unattended operation. These rules are now extended to cover computer installations as well, and in this respect, reliability analysis has proved to be a useful tool.

The introduction of computers onboard ships poses new problems to be considered. The two most important problems are respectively integration of alarm and safety functions in the computer system and the complex environment which is encountered.

The latier problem mostly concerns installation techniques and environmental testing, however, the first problem is of a more phiiosophical nature regarding systems analysis and design. In this context it is felt that the reliability characteristics of computer hardware alone is not a satisfactory measure of system utility. It is therefore proposed that an approach where the computer system is considered as an integral part of the ship is more realistic when evaluating the utility of a computer system.

The proposed analysis method combines conventional reliability calculations and risk value evaluation into a urility simulation of the computer system, based on the operational characteristics. An important part of the analysis is the establishing of a model of the computer system.

\section{METHOD OF ANALYSIS}

The proposed analysis method is intended to be a simple and practical tool in evaluating the utility of shipborne computer systems. The main features are the simplicity of the analysis and the combination of economic and reliability characteristics to provide a better basis for decision making.

Fig. 1 shows some of the elements contained in the analysis. 

ure or operational modes of the system. If the probability of being in a state oriy depends on the previous state and the transition probabilities between these states are independent of time, the hehaviour of the system describes a Markov chain. Given the failure model of the intended unit, the Miarkov chain will simulate the dynamic behaviour of the system, i.e. the transitions between the possible system states and the probabilities of the different operational modes.

\section{Cornputer task availabilities}

The traditional definition of reliability is impractical to apply to a computer system. This definition says that reliability of some device is defined as the probability the device will perform its function without failure for a specified periou of time under stated conditions. Becausc failure of hardware components does not automatically imply system failure or task failure, the concept of task availability is a better measure of system performance than hardware availability. Some of the system hardware states may leave a specified task completely intact, while others may only degrade the task performance. These states will be termed successful statcs for that particular task. The states complctely destroying task performance will be term: unsuccessful or critical states.

I et $P_{j}(t)$ be a column vector containing the probabilities of the successful states for task $j$ at time $t$. Let $D_{j}$ be another column vector containing numbers indicating the degree to which functional requirements of task $j$ can be accomplished in state $i, i \in$ (successful states) Then

$$
A_{j}(t)=P_{j}^{T}(t) \cdot D_{j}
$$

is a measure of the functional availability of computer rask $j$ at time $t$, given a specified software implementation. $A_{j}(t)$ may also be termed the system effectiveness for task $j$ at time t. Give a mission time $T$, the system/ mission effectiveness for task $j$ is:

$$
E_{j}=\frac{1}{T} \sum_{i=1}^{m}\left[\int_{t_{i}}^{t_{i+1}} A_{j, i}(t) d t\right] ;(2)
$$

where mission duration $T=\sum_{i=1}^{m}\left(t_{i+1}-t_{i}\right), m$ is the number oi mission phases and $t_{i}$ is the time at start of mission phase i.

Defining another column vector $\bar{D}_{j}=U-D_{j}$ where $\left[-\right.$ is a unit vector, and substituting $\bar{D}_{j}$ for $D_{j}$ in equation ( 1 ), gives:

$$
\bar{A}_{j}(t)=P_{j}^{T}(t) \cdot \bar{D}_{j}:
$$

where $\bar{A}_{j}$ is a measure of the unavailability of task $j$ at time $t$.

\section{Tracing failure consequences}

Extending the line of thought in evaluating task 
availabilities to estimate total computer system performance availability by a nondimensional "percentage" value vector like vector $D$, does not give the information one needs for inaking decisions on system utility. In addition, the computer system application and operational environment have to be baken into account.

Given the computer system tasks, their degree of back-up and the operational profile of the ship, a value can be assigned to each task by analysing the consequences resulting from the loss of each task. The consequences concern the whole ship and take the shape of events which may be of a more or less disastrous kind. Some of the se events are certain, and some are uncertain - the degree of uncertainty depending mainly on sailing characteristics, loading, geographical position and human interaction. The events can be damage to property, loss of time (off-hire) or inconvenience in the form of dispute, loss of reputation etc. .

Tracing the possible sequence of events resulting from loss of a specified computex task, can be accomplished by means of a logical consequence diagram. An estimation of the event sequences, their duration and probabilities can be performed without any knowledge of the failure process of the computer system hardware. The consequence analysis is therefore preferably performed by people with an intimate knowledge of sailing ships and ship operation and with access to damage statistic s. Usually several tasks can involve the same events, possibly with different probabilities. The different consequence diagrams thereby become coupled to each other.

\section{Evaluation of system utility.}

A11 events resulting from computer task failure are supposed to have a value, either instantaneous or time dependent. These values are independent of how the task failures were initiated and they are estimated from the direct costs associated to an event. The more inaccurate status vaiue of the circumstances connected to the event are also considered.

By collecting all events branching out from a task failure in a consequence diagram and making value estimates from event costs, probabilities and waiting times, a specific value is assigned to every computer task. Going back to the concept of task availability or system effectiveness, the task values are connected to the computer hardware as a measure of the failure consequences from hardware.

Defining the concept of utility as a numerical value of the prospect facing someone in a situation given certain assumptions, the task ralues can be inteipreted as the utility of the different computer systam hardware states, (1). Taking into account investment costs, the operating costs and the stochastic failure process of the 
hardware units, enables the analy st to evaluate the total computer system utility. $\dot{A}$ utility appraisal of the system can also be done without regarding the inveatment and operating cost.

\section{SIMULATION MODELS}

An important part of the analysis is the simulation of the failure behaviour of the computer hardware system. This produces the system state probabilities which are used as input to the system effectiveness calculations.

\section{The failure rate concept}

If $f(t)$ denotes the probability density function of a unit, then $f(t)$ dt is the probability that the unit will fail in the time interval(t, $t+d t)$. The probability that the unit will survive for the period $(c, t)$ is then:

$$
R(t)=1-\int_{0}^{t} f(x) d x=\int_{t}^{\infty} f(x) d x ;
$$

which means that:

$$
-\frac{d R}{d t}(t)=f(t)
$$

The failure rate $z(t)$ of the unit may be defined as the conditional probability that the unit will fail in a time interval $(t, t+d t)$, given that it has survived up to time $t$ :

$$
z(t)=\frac{f(t)}{R(t)}=\frac{d}{d t} \quad(\ln R(t)) ;
$$

Assuming the hardware units in the computer system to be subject to chance failures only, the failure rate for each init is assumed constant: $z(t)=\lambda$, and the expression of reliability in equation (4) becomes:

$$
R(t)=e^{-\lambda t} \quad, \text { since } R(0)=1 ;
$$

Because the conditional probability $2(t) \cdot d t=$ $\lambda \cdot d t$ depends only on $d t$ and is independent of $t$, the expected life time of a un:t, MTTF, is constant at all times and equal to the reciprocal of the failure rate:

$$
\operatorname{MTTF}=1 / \lambda
$$

This implies that if the independent units composing the computer systam have exponentialiy distributed times to failure, then the tirne to system hardware failure will also be exponentially distributed. For repairable units, the assumption of constant faiiure rate $\lambda$ and repair rate $\mu$, means that cperating time between hardware unit failures and the time required for repair (MTTR) of each unit composing the system, are sxponentially distributed.

\section{The Markov Model}

Having defined a state space for the computer system, a Markov process is one whereby the system occupies a certain state and either undergoes a transition from this state to another, or remains in its present state with time homogeneous transition probabilities which only de- 
pend on the previous state.

The Markov chain defined by a discrete state space and continuous time parameter is a stocastic model very suitable in describing the behaviour of complex systems.

Let $\mathrm{p}_{i}(\mathrm{t})$ denote the probability that the system is in a state $i$ at time t. For a state space containing a finite and countable number of states N, obviously

$$
\sum_{i=1}^{N} p_{i}(t)=1
$$

Let $P(t)$ be a column vector whose elements are the syetem state frobabilities at time $t . P(t)$ may be called the state vector. The transition probabilities or ratep in the Markoy chains will consist of the repair and failure rates of the actual computer system as previously defined. The requirement of time homogenity is fulfilled by the exponential density functions for time to failure and time to repair. Use of the Chapman Kolmogorov differential equation gives

$$
\frac{d}{d t} P(t)=(M) \cdot P(t):
$$

where (M) is the NxN matrix of the transition rate. $B$.

Knowing the initial conditions given by the state vector $P(0)$, the set of simultaneous differential equations can be solved, and the probability vector for the system states is obtained as a function of time.

The transition rate matrix $(M)$ is the basic element in the Markov model, and it characterizes both the system being analysed as well as the analysis.

If the computer system is repairable in all state $e$ containing failed hardware unito, i.e. all states communicate, then the transition matrix and the states are called ergodic or positive : ?current. State which are not ergodic, are called transient.

In a completely ergodic proces, the limits:

$$
\lim _{t \rightarrow \infty} P_{i}(t)=P_{i}
$$

exist for all states $i$ in the state space. As

$$
\begin{aligned}
& t \rightarrow \infty \quad, \text { equation (10) becomes: } \\
& (M), P=0
\end{aligned}
$$

Together with equaticn (9) this equation implies that the limiting state prohabilities can be determined by solving a set of linear alfyebraic equa tions.

A useful tool in Markov analy sis is to prepare a diagrammatic representation of the tranaition rate matrix $(M)$. The graph is called a reliability trangition diagram, and it is composed of nodes representing system sates and branches representing the possible transitions between the 
state 3 . Labelling the branches with transition rate $B$ makes it quite simple to evaluate the elerents in (M). Examples of Eransition diagrams are given in fig. 4 and $\mathrm{fig} .5$.

\section{Computer programs}

In crder to cope with the problems of solving the eq.lation systems of equation (10) and $(12$ and 7 ) in a fast and economical manner, two computer programs have been developed, REAVAN and STAVAN (2).

The program REAVAN solves the set of differential equations given by equation (10), utilizing the Kutta-Merson algorithm. The result is the probability otate vect or $P(t)$ as a function of time, for a finite time period with specified time intervals.

The program STAVAN solve the set of lineax algebraic equations given by equations (9) and (12). The solution technique is based on an optimal Jordan elimination process, and the result is the steady-3tate probability vector $P$ and the waiting times between different specified subsets of states.

Both programg are written in the ALGOL programming laxguage for UNIVAC il 107 and 1108 computers with EXEC 8. Some of the Bubroutines involving manipulation of matrices are, however, written in FORTRAN IV. The programs have proved to be extremely helpiul in evaluating system state probabilitieg. Comput.ing time being. only a few seconds, the programs are economical to run and give a lot of information in ohort time.

\section{APPLICATION OF THE ANALYSIS METHOII TO}

\section{. DESIGN STUDY}

Given an actual ship and the tagks to be performed by the computer system, an example w:11 be given, showing how use of the described method can be used to increase the utility of a system at the design stage. This is done by assigning redundancy, eliminate bottle-necks and allocate spare parts with respect to the ship's function and environmental conditions.

\section{The ship system and cost yalues}

The ship system to be considered is a machinery plant, with special emphasis placed on the pro. putaion machinexy. Supervision and control of the machinery (referred to as the EO tasks) and condition monitoring (Feferred to as $C M$ ) are the main tasks to be performed by the computex sy stem.

The analysis method allows partition of the analysis into two groups, or submodels of the overail system. One consists of the computer system including the tasks to be performed. The other is the ship oystem which defines the computer tasks. Description of the ship system and the assigning of cost values to the different tasiks to be performed by the computer system, will 
not be shown here. The value eqcimation can best be done by personnel with experience in and knowledge of sailing ships and ship machinery plants, since the value estimation is independent of the computer configuration.

The cost estimation must take account of sailing schedules, harbourage, type iff ship etc.. Stop of main propulsion involves greater risk, i.e. expected cost, to the ship when manoeuvring in restricted water than when sailing in open sea.

For the estimation of the different cost values, a typical voyage of 24 days in open sea, 4 days in restricted waters and two days in harbour is taken into consideration, (3).

The time dependent and immediate values for ioss of compuser tasks are shown in table 1. These values are valid for all four system alternatives outlined in the foilowing.

\section{The basic computer system}

The starting point in this design study is the basic computer system A, shown in fig. 2 . It consists of a compater (COM) (CPU, memory, interface for typewriter, punch, tapereader, computer operator panel etc. ) and a typewriter (TW). Further there is a control console (CC) connecter? to the computer through the process input/output system (PIO). A display (CRT) is also connected through the PIC. A tapereader (TR) is used for loading programs into the com- puter, and the rohole computer system is sed by power from the main switchboard (MSB). No tapepunch is shown since it is not necessary for the overall syotem function.

The failure and repair data used in this analysis are estima ted afte:- commlinication with designers of related systems. The main input data to the computer programs REAVAN and STAVAN जre the mean time between failure (MTBF) and the mean time to repair (MTTR) for each component in the system. In table 2, the columns 3 and 4 show data valid for the basic system $A$. (The table also includes data used for the systern a B, C and D. )

The basic system is supposed to consist of seven independent units (see fig. 2). Each unit is cansidered to be in only one of two states, operating or failed. The system may therefore enter $2^{\%}=$ 12.8 different states. Since the MTBF is much larger than the MTTR for all units in the system every combination of unit failures yielding con. requences less severe than the consequences of each subset within the combination are neglected. Figure 4 shows the reliability transition diagram for the basic system A. Only 9 states are considered to be of interest. The states $2,3,4$ and 5 will cause 1088 of all computer tasks.

Some results obtained from the computer program REAVAN are shown in fig. 6,7 and 8 for all four sysiem configurations. In fig. $6 a$, the 
dynamic behaviour of the probabilities of system success are plotted. The steady state availabilities for repairable systems are reached in approximately 8 to 12 hours after starting the systems. Fig. $6 \mathrm{~b}$ shows the corresponding probabilities of computer failure which is a critical failure mode. In measuring the utility value of the system, a.o. equation (3) is used to compute the task value function for the system. The simple decision table, table 3, shows the connection between hardware failures and total or partial loss of computer tasks. Decision tables are used to prepare information for input to computer programs calculating utility values.

The calculated utility values for 1088 of 8 ytem performance are shown in fig. 7. In fig. 8, the fasik availabilities are shown as calculated by the computer program STAVAN,

\section{Analysis method}

The three system configurations $B, C$ and $D$ are modifications of basic computer aystem $A$. The objective is to irnprove the availability of the computer tasks, thus decreasing the overall risk utility. Experience has shown that the power supply from the main switchboard is critical. Use of this power supply causes the MTTF for several units, expecially the cornputer and tape-reader, to decrease to a value much below the corresponding value for landbased computer syotems.
Feeding power continuously through a battery bank to the computer aystem, improves the MTTF for several units, gee 5 th and 6 th column in tabie 2. Additionaily, the battery power supply guarantees the system continuous power for at least $30 \mathrm{~min}$. if a main switchboard breakdown occurs. The addition of a battery supply to system A gives ; stem B.

Table 4 shows that the EO and CM tasks depend heavily or precige function of the typewriter. The table also shows that no reconfiguration of the program system can be performed without proper function of the tare-reader. Usually, typewriters are equipped with siow tape-readex Modifying the soficware and hardware oystem in such a way that the tape-reader on the typewriter can be used as back..up, and adding an extra typewxiter for redundancy, we call the new configuration system $C$.

Again, calculations on the modified computer system show an improvement of the utility func. tion in spite of a small decrease in the steady state and dynamic availability of the computer hardware. According to table 5, the only "Sottle-necks" remaining are the computer itself and the process input/output system. These are the only units which by a aingle failure can cause tota? gystem break-down.

The failure consequences presented in table 1 , show that the EO-taskg are much more impor - 
tant than the CM-tasks. U sing two computer 8 , one for the EO-tasks and the other for the CMtagks, are giving back-up for the EO-computer tasks at the expense of the CM-tasks. This also results in a higher MTTF for each compute $r$ ir this new oysters compared to the com. puters in syotem $A, B$ and $C$, owing to reduction of the memory capacity of each computer. Uoing this modification, a data chasmel (ACM) is needed for communication between the two computers.

In the process I/O syotem, the multiplexers and converters are some of the most unreliable parts. The I/O system is divided into three parta. Two identical parts, containing the most unreliable part of the $1 / O$ system, serve each of the two computers. The part serving the less important computer will serve zs a stand-by unit for the most important computer (EO-tasks). The third part of the $I / O$ system is quite reliable, so this remaining bottle-neck is acceptable irom a reliability point of view.

A block diagram for this system, containing 13 units, is shown in fig. 3. Theoretically, the system can enter $2^{13}=8192$ different states, but without loss of any significant infor.. mation, the method applied allowe for a reduction to only 28 states. The reliability trimsition diagram for system $D$ is shown in fig. 5 .

The improvement in risk utility from system A to system $D$ is shown to be a factor of 2.5 (fig. 7). with a corresponding increase in task availability.

Hitherło, we have assurned that all bystem failuxes have been repairable with a MTTR given in table 2. Thiz will not always be true, especially for computer sy stems onboard ships due to lack of specialists, tools, spare parts etc. In order to demonstrate a way of allocating spare parts, calculations have been performed assuming that the CRT display, battery power supply and two identical parts of the $i / O$ system are not repairable (absorbing states). The results are plotted into fig. $6 a$.

\section{CONCLUUSION}

In the preceeding sections, an analyeis method intended for evaluation of computer systems on board, has been presented. The procedure may geem somewhat complex at first, but it has bcen found to be a simple and efficient way of obtaining information on computer aystem st'uctures. It is felt that reliability data alone are not aatisiactory as a basis for selecting between alternativo system configurations. The concepts of utility and task values, however, prove to provide information relevant to systems evaluation and design.

Application of Markov models has been found to constitute a very convenient analysis tool in 
system s design, because:

$\therefore$ The concept is easy to understana.

- The molel is easy to use.

- The state space is eary to change.

- The system atructure is easy to change.

- Alternative syotema are easily compared

- Sensitivit analysis is easy to perform.

- Computer analysis takea oníy a few secinds.

Even if the Markov chains in some cases may not be the corret stoohatic deacription of the syetem, it still gives information enabling comparative analysis of́ systems.

\section{REFERENCES:}

(1) H. Chernoff and L. E. Moses: "Elementaxy Decision Theory".

John Wiley \& Sons Inc., New York 1959.

(2) Tor-Christian Mathiesen: "Reliability Engineering and Ship Machinery Plant Design". Lic. Techn. Thesis.

(3) T. Heimly, G. Dabll, C. Bøє: "Reliability and Avzilability of Computer Systems onboard Ships" (In Norwegian). Report from Det nor ske Veritas, Machinery department 1972.

\begin{tabular}{|c|c|c|}
\cline { 2 - 3 } \multicolumn{1}{c|}{} & $E 0$ & $C M$ \\
\hline $\begin{array}{l}\text { Immediste } \\
\text { vaice }\end{array}$ & $2.7 \cdot 10^{4}$ & 0 \\
\hline $\begin{array}{l}\text { Tims depen- } \\
\text { dens value }\end{array}$ & $97 \cdot 10^{6}$ & $0.21 \cdot 10^{4}$ \\
\hline
\end{tabular}

Table 1. Value for computer tasks.

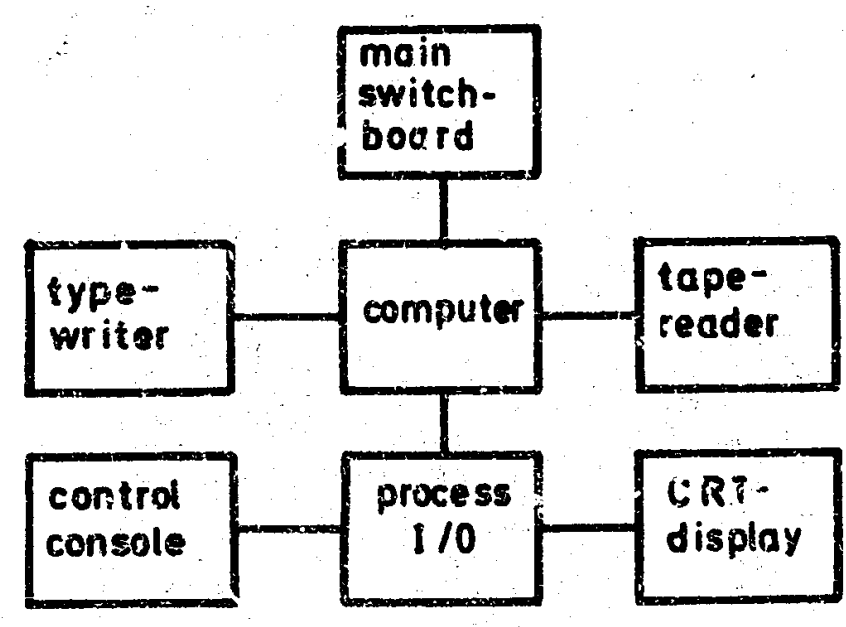

Fig 2. Ecsic computer system A

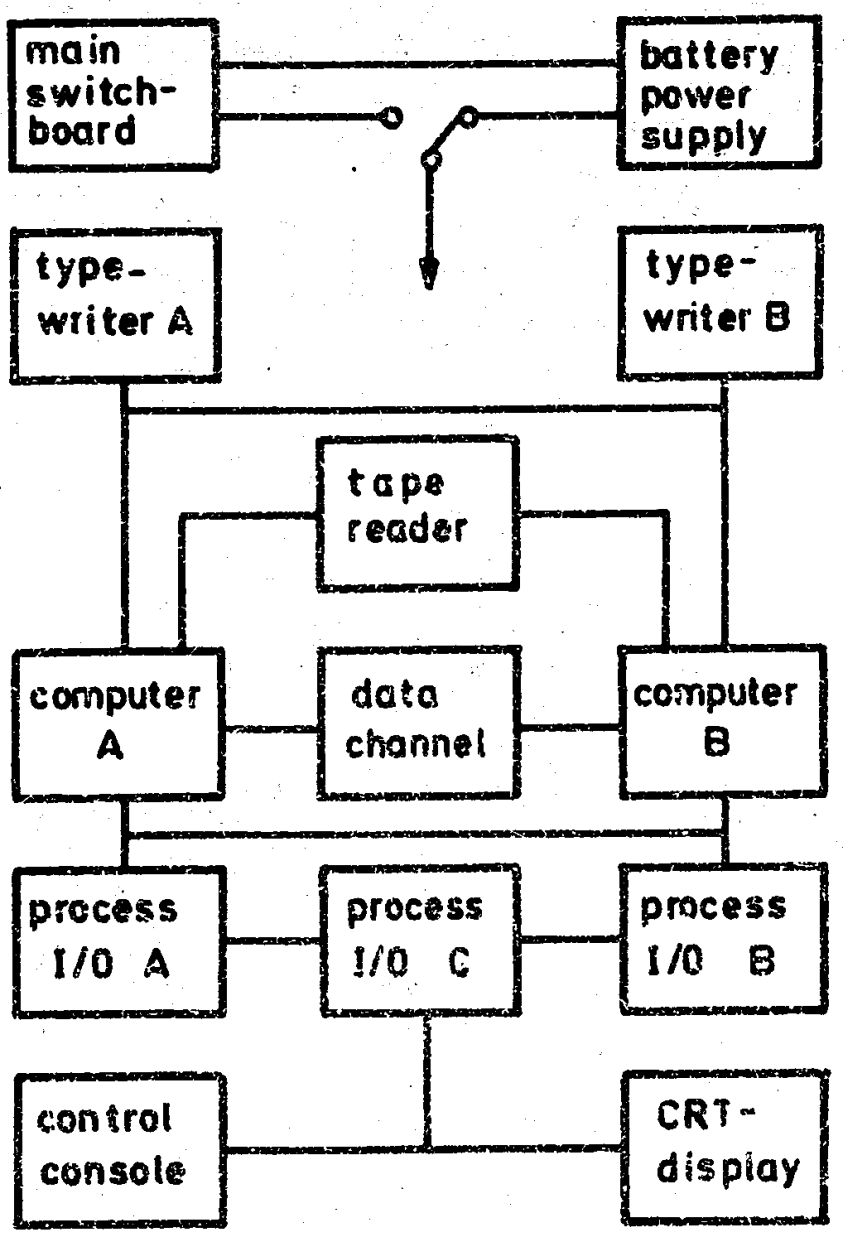

Fig. 3. Computer system D 


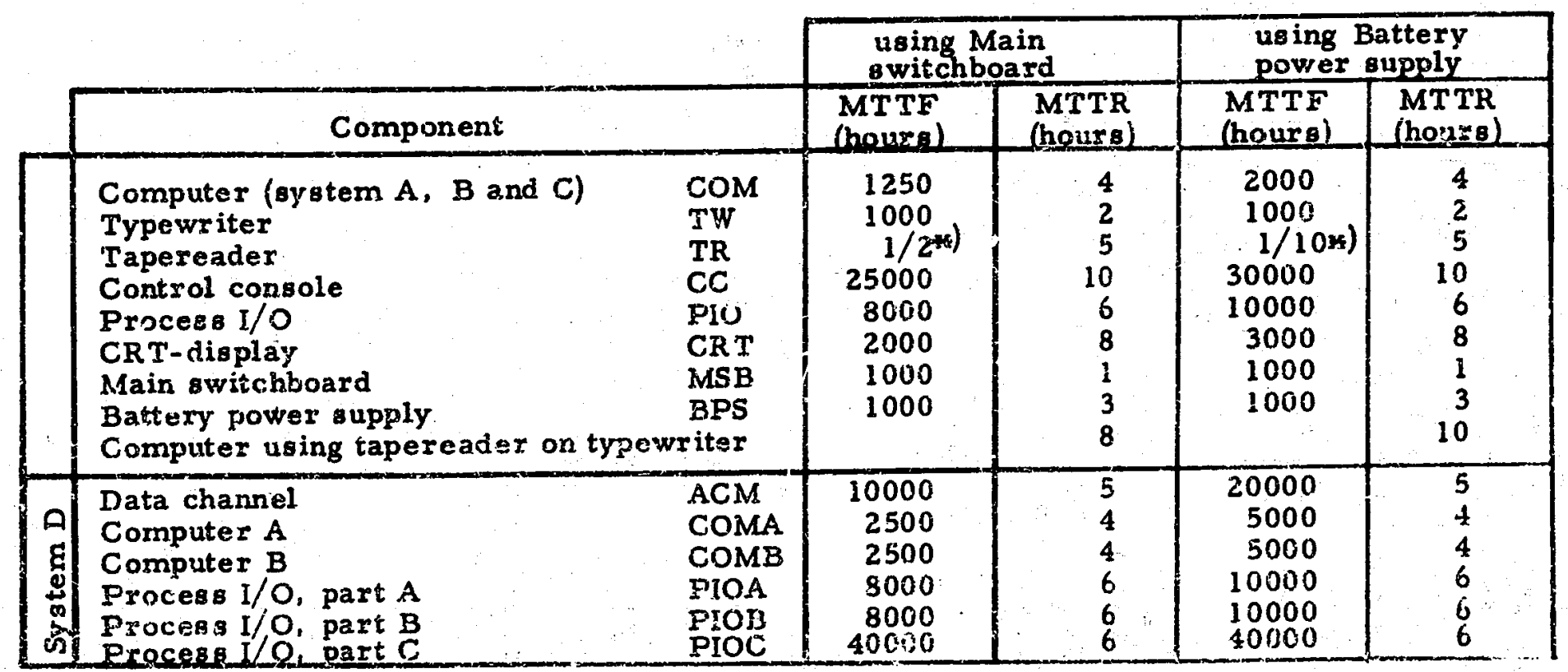

*) failure every and or 10 th time when used.

Table 2 Failure and repair data

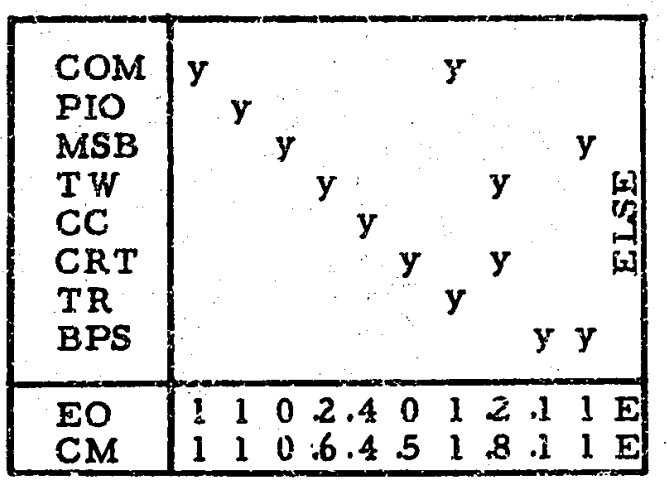

Tabie 4. Decision table, systern 5

( $E=$ errox, consice $r^{\text {ing }}$ not allowed states)

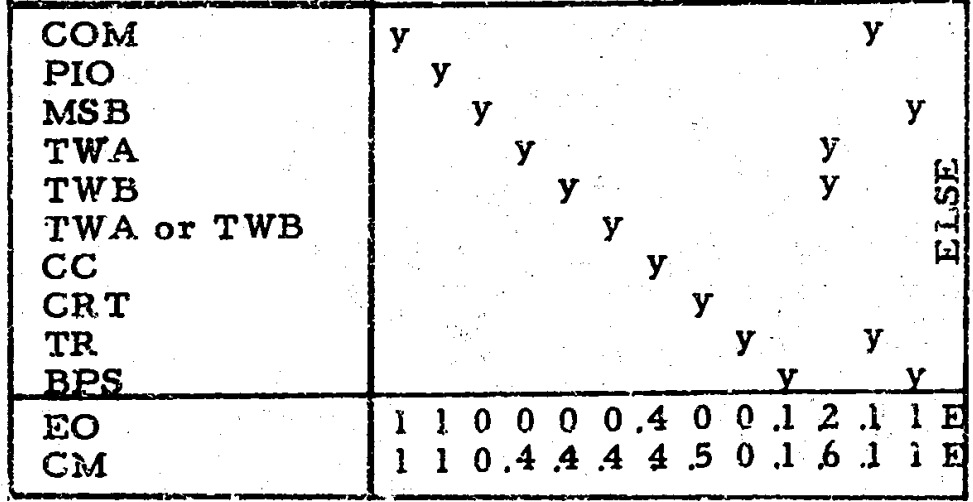

Table 5. Decision table, system C

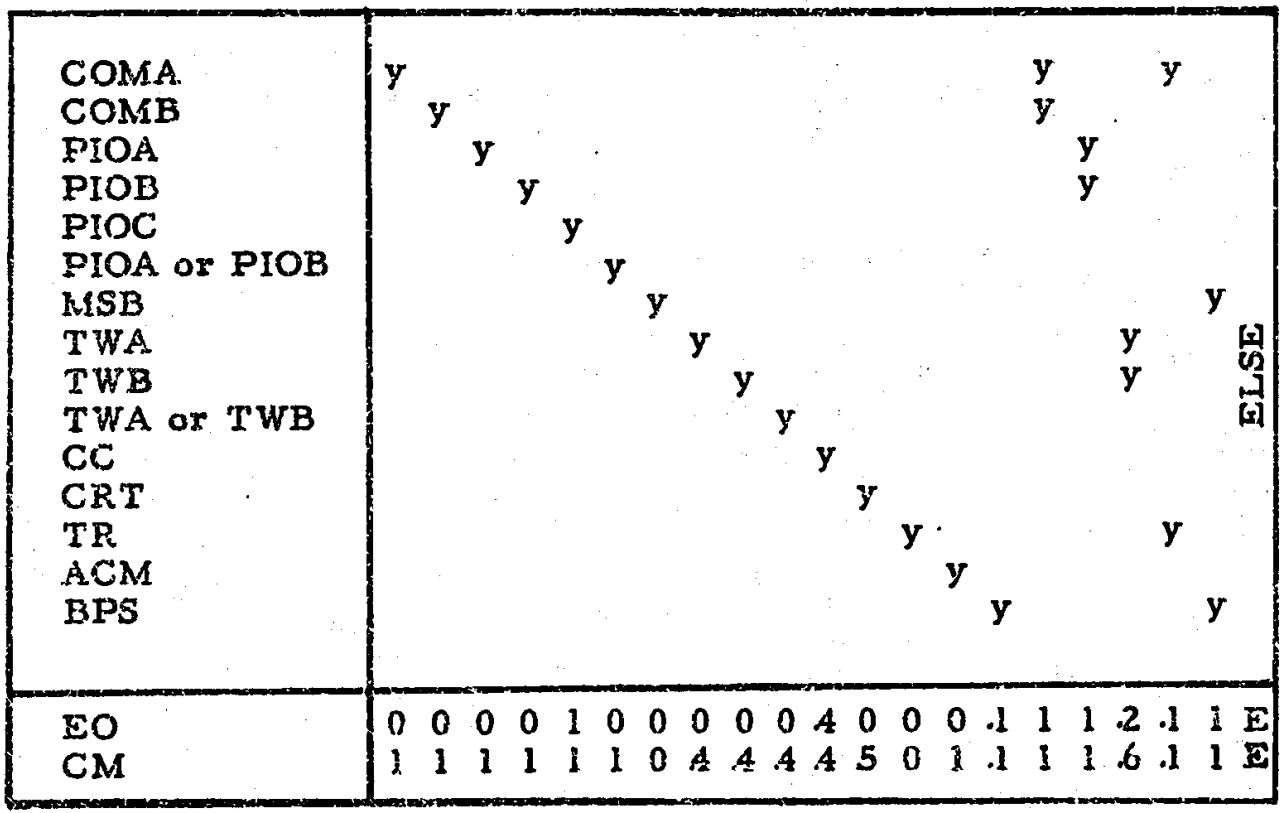

Table 6. Decision table, system D

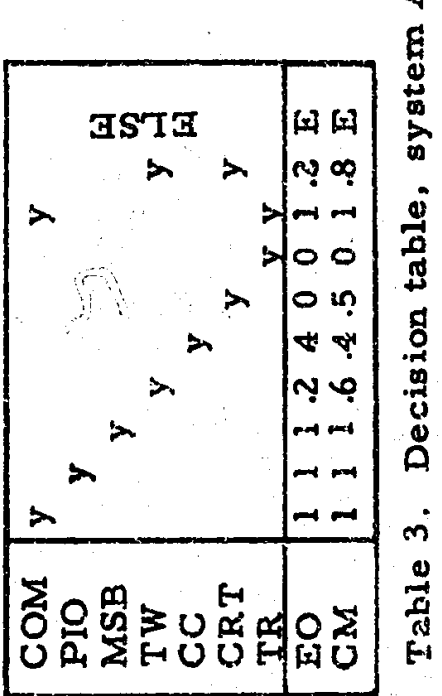




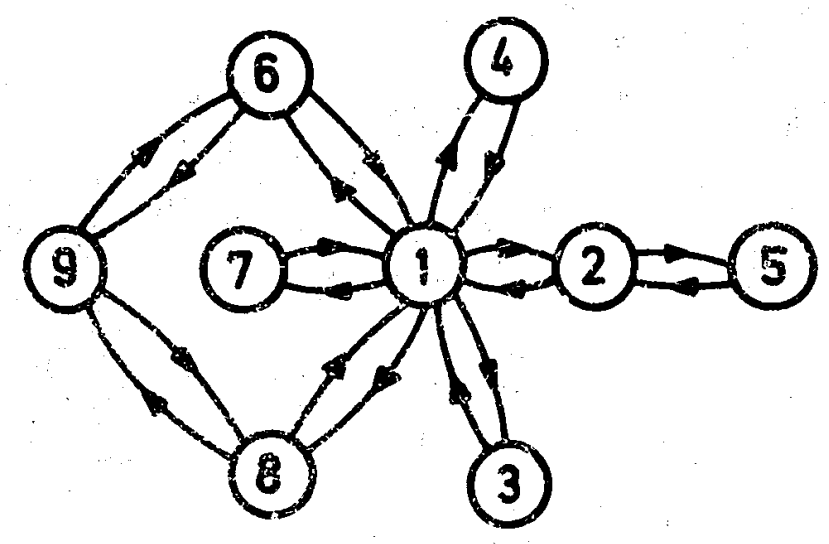

1. System o.k.

2. Computer fault

3. Prorese I/O fault

4. Mair awitchboard fault

5. Computer and tapereader fault

6. Typewriter fault

7. Control console fault

8. CRT-display fauli

9. CRT and typewritex fault

Fig. 4. Reliability fransition diagram for system $\mathbf{A}$.

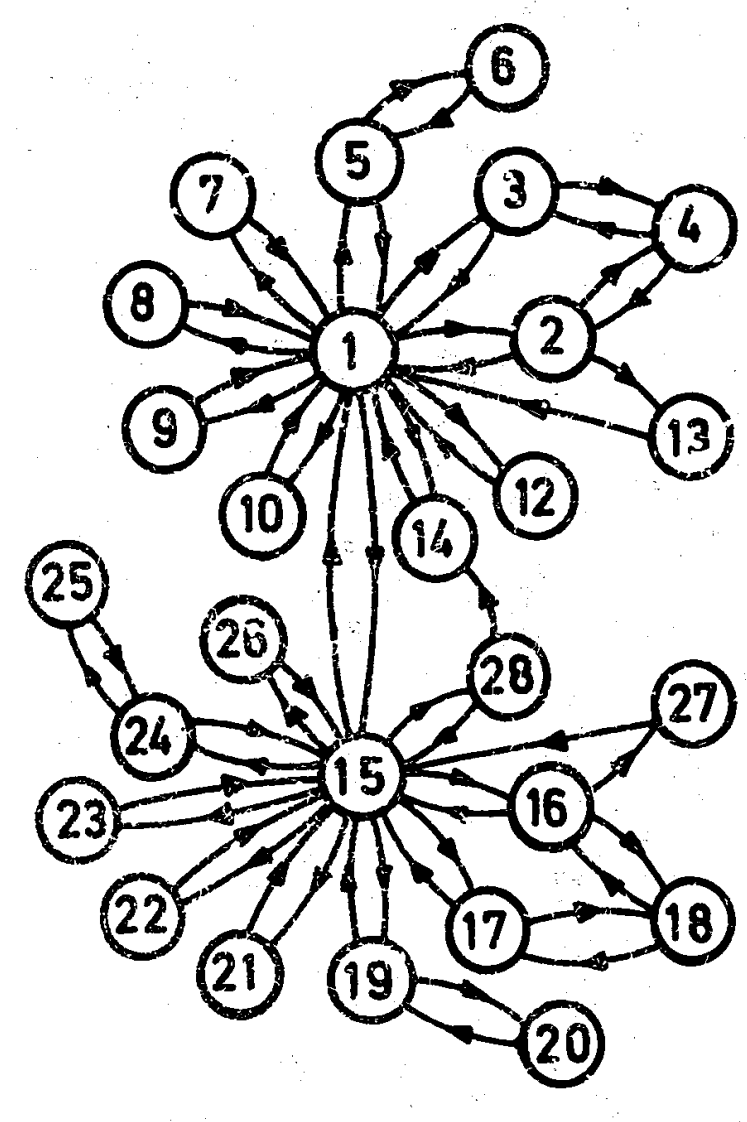

1. Systeri o.k.

2. Computer A fault

3. Computer $B$ fault

4. Computer $A$ and $B$ favlt

5. Typewriter $A$ or $B$ fault

6. Typewriter $A$ and $B$ fault

7. Control console fault

8. CRT-display fault

9. Process $I / O \mathrm{C}$ fault

10. Process $1 / O$ A or $B$ fault

11. Process $I / O A$ and $B$ fault

12. Data channel fault.

13. Cornputer A and tapereader fa:lt

14. Main switchboard fault

15. Battery powrer aupply fault

f 16. Computer A fault

17. Computer $\mathrm{B}$ fault

- 18. Computer $A$ and $B$ fault

है 19. Typewriter $A$ or $B$ fault

20. Typewriter $A$ and $B$ fault

a 21 . Control console fault

22. CRT-display fauli

23. Process I/O C fault

24. Process I/O A or B fault

25. Process I/O $A$ and $B$ fault

26. Data channel fault

\pm 27. Computex A and tapereader fault

कึ $[28$. Main switchboard and battery power supply fault

Fig. 5. Reliability transition diagraxa for system $D$. 


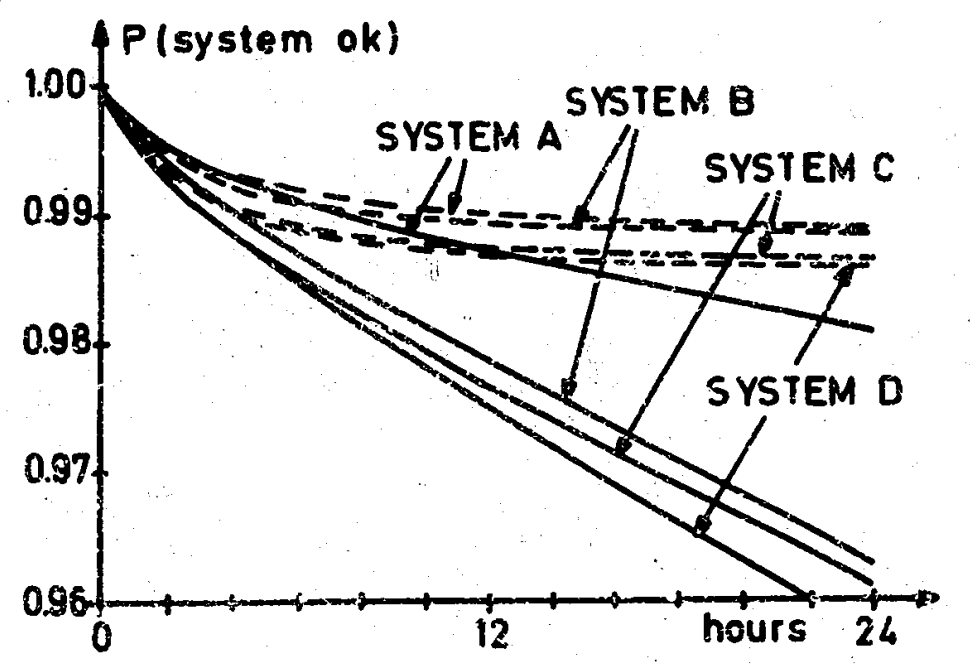

Fig. 6 D Dynamic behavior of systems as calculated b: REAVAN

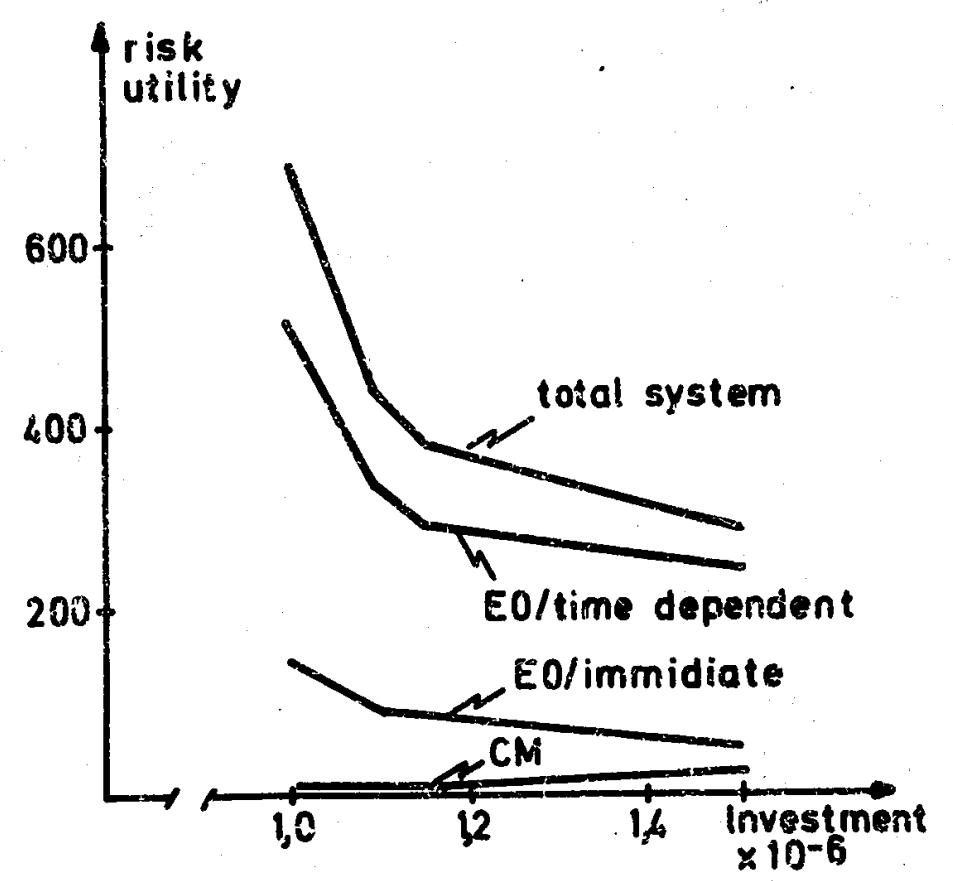

(SYSTEM:) (A) (B) (C) (D)

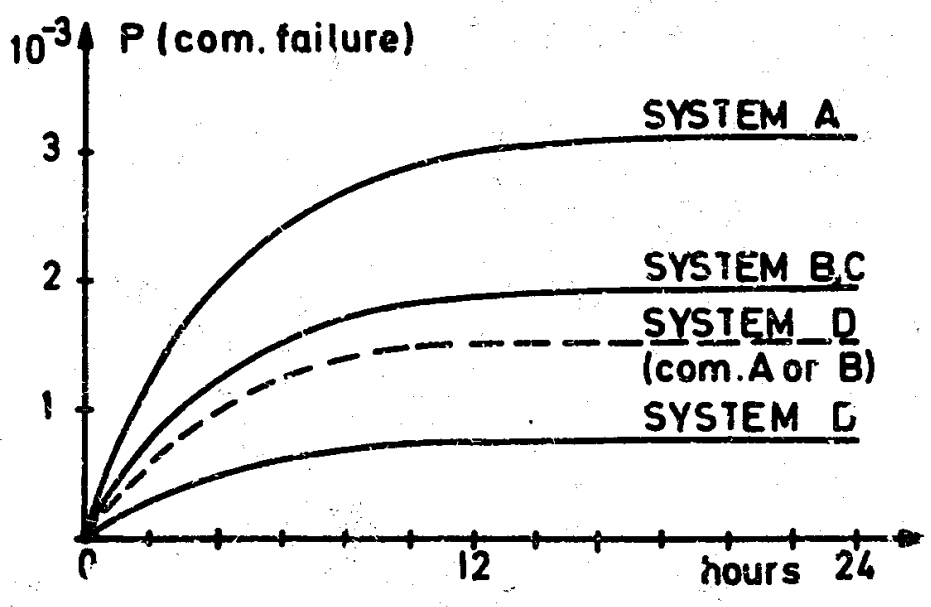

Fig. 6b Probability of computer failure as calcuinted by REAVAN

Fig. 7. The utility function

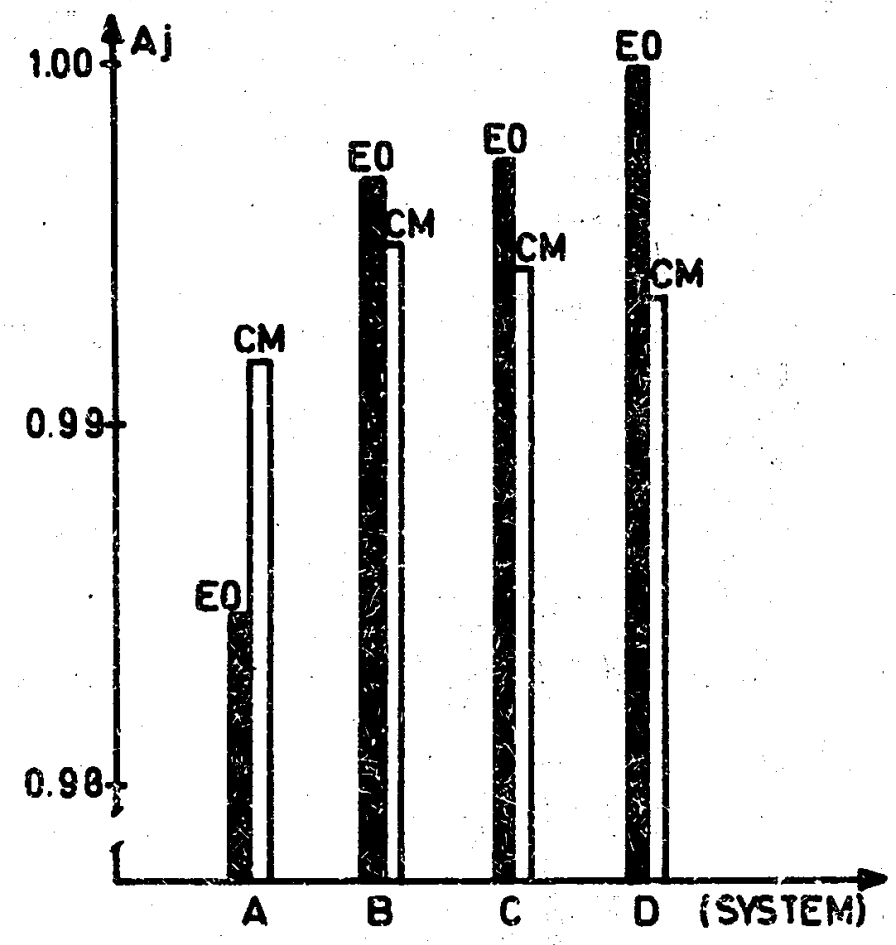

Fig. 3 Task availabilities as caiculated by STAVAN 